\title{
Exploring fracture risk factors among Omani women: Implications for risk assessment ${ }^{*}$
}

\author{
Melba Sheila D’Souza\#, Chandrani Isac, Ramesh Venkatesaperumal, Anandhi Amirtharaj, \\ Anitha Thanka, Shreedevi Balachandran, Huda Al Noumani
}

Department of Adult Health and Critical Care, College of Nursing, Sultan Qaboos University, Muscat, Sultanate of Oman Email:"

Received 7 September 2012; revised 16 October 2012; accepted 25 November 2012

\begin{abstract}
Osteoporosis is common among postmenopausal women, giving rise to morbidity and diminishing the quality of life. There is lack of information about the risk factors of Osteoporosis among local Omani women. The aim was to explore the risk factors of Osteoporosis among Omani women using a Modified Fracture Risk Assessment Tool. This is an exploratory research design using a simple random sampling. A pilot study was conducted among 35 local Omani women from the Muscat region, who completed the validated and reliable Modified Fracture Risk Assessment Tool (MFRAT). Bone Mineral Density (BMD) was measured among 11 women at moderatehigh risk based on MFRAT. The data was analyzed using inferential statistics. Fourteen Omani women were at moderate-high risk for Osteoporotic fracture due to factors related premenopausal, Vitamin D deficiency, increased parity, increased lactation period and sedentary lifestyle. Among these five women had low BMD and required early intervention and support. Determinants of Osteoporosis can be assessed among premenopausal Omani women with a specific risk assessment tool. There is a need to construct a culturally sensitive risk assessment tool for Omani women for early screening and detection of Osteoporosis. Nurses can identify, provide intervention and education for Omani women at-risk of fracture.
\end{abstract}

Keywords: Fracture Risk Assessment; Osteoporosis; Osteopenia; Omani Women; Early Identification; Early Screening; Bone Mineral Density; Nursing Care; Primary Prevention

\footnotetext{
"The authors declare that they have no competing interests.

This study was approved by the College Research and Ethics Committee.

This pilot study was funded by the College of Nursing, Sultan Qaboos University.

"Corresponding author.
}

\section{INTRODUCTION}

Osteoporosis (OP) is a metabolic bone disorder characterized by low bone mineral density (BMD) and deterioration of bone structure (bone quality), resulting in an increased susceptibility to fractures of the hip, spine, and wrist [1]. Worldwide, approximately one-third of women aged 60 - 70 years and two-thirds of women aged 80 and older have Osteoporosis. Lifetime risk of fracture for a 50 -year-old White woman is estimated at over $70 \%$; her risk of hip fracture alone is about $14 \%$ [2-4]. An Osteoporotic fracture occurs every three seconds, with one in three women over 50 years of age expected to be burdened with a fracture at some point [5]. The World Health Organization (WHO) considers osteoporosis to be second only to cardiovascular disease as a public health concern [6,7]. In the Middle East life expectancy has increased with rising urbanization, advance technology and health care, thus, escalating the risk factors of occurrence of Osteoporosis.

Omani women usually wear an external gown on top of the regular clothing made of black velvet, silk or coloured (abhaya) that covers the whole body, a black or coloured scarf covering the head and neck (veil or shiela) and sometimes veils which cover the face or eyes, gloves and stockings. Thus skin exposure is very limited to the exposed areas [8]. Omani women have an increased vulnerability to the risk of fracture as a result of less exposure to Vitamin D, calcium deficiency and sedentary lifestyle. They have an increased predisposition to develop OP, which has significant long term risks. Changes in life-style practices are likely to be influenced by these women's perception of health, choices, autonomy and control over resources. Their health behaviours are also influenced by socio-economic, cultural, religious, and gender norms. Several risk factors often coexist to increase the risk of OP substantially among women. Primary care interventions are directed to identify women at increased risk before the symptoms develop, whilst primary care nurses should be vigilant to assess women with suspected fragility fractures or risk for falls. In the 
absence of fracture registry in most Middle Eastern countries, the data available from this region are limited. Hence, there is an immediate need for periodic fracture risk assessment among Omani women and to engage in health seeking behaviours to reduce the care giver burden and cost of health care. The aim of this study was to explore the Osteoporotic risk factors among Omani women for the development of a culturally specific risk assessment tool.

\section{OBJECTIVE}

To explore the significant risk factors of Osteoporotic fracture among local Omani women using a Modified Facture Risk Assessment Tool.

\section{METHODS}

This is an exploratory research design to explore the risk factors of Osteoporosis among local Omani women using a Modified Fracture Risk Assessment Tool (MFRAT) and bone mineral density (BMD). We have reviewed the literature and standard risk assessment tools for Osteoporosis or fracture among women in the Middle East and worldwide. The World Health Organization (WHO) FRAX (Fracture Risk Assessment) tool [9-11] was developed to evaluate fracture risk using 12 parameters $[12,13]$, the Osteoporosis Risk Assessment Instrument [14] has 3 parameters, the screening assessment for preventing falls has 12 parameters, the Osteoporosis self-assessment tool for Asians and the Khon Kaen Osteoporosis Study Score have age and weight parameters $[15,16]$.

We developed a Modified Fracture Risk Assessment Tool (MFRAT) based on the standardized tools and literature search. The MFRAT has 11 parameters: Osteoporosis, Vitamin D Deficiency, previous fracture, long term medications (Steroid, Anticonvulsants, Estrogen, Hormone Replacement Therapy, Heparin, Thyroxine, Vitamin D, Hypoglycemics or Calcium), family/maternal history of Osteoporosis or pathological fracture, lifestyle, smoking cigarette or sheesha, alcohol, use of dairy products, exercise, number of children, lactating period and menstrual status. The MFRAT-English version was translated to Arabic version by linguists and then back translated. The content validity was done by 5 subject experts in the field. The reliability of the tool $(\mathrm{r}=0.81)$ was done among 15 Omani women in Muscat. The tool was found to be valid, reliable, appropriate and feasible for the study. Moderate-high risk scores on the MFRAT (low: 0 - 9; moderate: 10 - 19; and high risk: 20 - 34) were used to select women for BMD testing. BMD $\left(\mathrm{g} / \mathrm{cm}^{2}\right)$ is measured by dual energy x-ray absorptiometry (DEXA) scan using a T-score of the lumbar spine/hip and/or femoral neck as the gold standard. The lower the
BMD score the greater the risk of fracture. Osteoporosis is defined as bone mineral density that is 2.5 standard deviations or more below the mean for a young adult. There is a statistical association between poor bone density and higher probability of fracture [1].

The inclusion criteria was Omani women aged more than 20 years of age (Osteoporosis has a prevalence $<1 \%$ in women $<45$ years) and voluntary participation. The exclusion criteria were pregnant Omani women and above 80 years. An ethical approval was obtained from the College Research and Ethics Committee in July 2011. One health center was selected randomly among the four health centers in the Muscat region. A pilot study using simple random sampling was done to select thirty-five (35) Omani women in this health centre. The selected women were explained and provided a written valid document regarding the purpose, protocols, study tools and the data collection methods. The women were informed by the concerned radiologists that the BMD testing was a painless, non-invasive, had low radiation and no known side effects compared to the benefits $[15,16]$. The women were free to withdraw from the research at any time, with complete benefits of medical care, treatment or legal rights. An informed verbal and written consent was taken from the women who were willing to participate in the study. These women were administered the Modified Fracture Risk Assessment Tool (MFRAT). All the data were treated confidentially and stored in sealed cabinets. Bone Mineral Density (BMD) was measured among 11 women at moderate-high risk based on MFRAT. The data was analyzed using inferential statistics.

\section{RESULTS}

Personal characteristics based on MFRAT and BMD (Table 1). Among the 35 women, only $22.9 \%$ (45.5\%) were in the menopausal age ( $>40$ years) and $34.3 \%$ (34.3\%) had low body weight ( $<60 \mathrm{~kg} / 125 \mathrm{lbs})$ based on the MFRAT and BMD scores respectively. $28.6 \%$ $(72.7 \%)$ of the women were not regular consumers of dairy products, $14.3 \%(45.5 \%)$ required arm support to raise themselves from a chair and $45.7 \%(100 \%)$ did not perform any exercise. The data shows low BMD among women with moderate-high risk factors of fracture.

Clinical characteristics based on MFRAT and BMD (Table 2). 8.6\% (27.3\%) of the Omani women had Osteoporosis and $20 \%(45.5 \%)$ had systemic illness while $17.1 \%(54.5 \%)$ were on long term medications based on the MFRAT and BMD scores respectively. There was "history of fracture after 40 years" among these women $(11.4 \%, 36.4 \%)$, their mothers $(22.9 \%, 63.6 \%)$ and family $(8.6 \%, 27.3 \%)$. There were significant factors governing the risk or development of Osteoporosis like predominance of pre-menopausal women $(62.9 \%, 63.6 \%)$, 
Table 1. Personal characteristics among Omani women.

\begin{tabular}{|c|c|c|c|c|c|c|}
\hline \multirow{2}{*}{ Personal Characteristics } & \multirow{2}{*}{ Categories } & \multicolumn{2}{|c|}{ MFRAT $(\mathrm{N}=35)$} & \multicolumn{2}{|c|}{$\operatorname{BMD}(\mathrm{N}=11)$} & \multirow{2}{*}{$\mathrm{p}$} \\
\hline & & $\mathrm{F}$ & $\%$ & $\mathrm{~F}$ & $\%$ & \\
\hline \multirow{3}{*}{ Age in years } & $20-29$ & 13.0 & 37.1 & 1.0 & 9.1 & \multirow{3}{*}{0.54} \\
\hline & $30-39$ & 14.0 & 40.0 & 5.0 & 45.5 & \\
\hline & $>40$ & 8.0 & 22.9 & 5.0 & 45.5 & \\
\hline \multirow{3}{*}{ Weight in $\mathrm{Kg}$} & $<60$ & 12.0 & 34.3 & 5.0 & 45.5 & \multirow{3}{*}{0.58} \\
\hline & $60-69$ & 5.0 & 14.3 & 2.0 & 18.2 & \\
\hline & $>70$ & 18.0 & 51.4 & 4.0 & 36.4 & \\
\hline Smoking/alcohol consumption & No & 35.0 & 100.0 & 11.0 & 100.0 & - \\
\hline \multirow{2}{*}{ Regular use of dairy products } & Yes & 25.0 & 71.4 & 3.0 & 27.3 & \multirow{2}{*}{0.71} \\
\hline & No & 10.0 & 28.6 & 8.0 & 72.7 & \\
\hline \multirow{2}{*}{ Arm support to raise from a chair } & Yes & 5.0 & 14.3 & 5.0 & 45.5 & \multirow{2}{*}{$0.07^{* *}$} \\
\hline & No & 30.0 & 85.7 & 6.0 & 54.5 & \\
\hline \multirow{3}{*}{ Regular exercises/mobility } & Never & 7.0 & 20.0 & 6.0 & 54.5 & \multirow{3}{*}{$0.08^{* *}$} \\
\hline & $1-2$ times/week & 9.0 & 25.7 & 5.0 & 45.5 & \\
\hline & $>3$ times/week & 19.0 & 54.3 & 0.0 & 0.0 & \\
\hline
\end{tabular}

${ }^{* *}$ Significant at $\mathrm{p}<0.10$. Modified Fracture Risk Assessment Tool (MFRAT), Bone Mineral Densitometry (BMD), F-Frequency.

Vitamin D Deficiency $(37.1 \%, 54.5 \%)$, increased parity $(22.9 \%, 54.5 \%)$ and longer lactating period $(45.7 \%$, $54.5 \%$ ). The data shows low BMD among Omani women with moderate-high risk factors for Osteoporosis.

Association between the fracture risk factors and characteristics (Tables $\mathbf{1}$ and 2). There is a significantly high association between the fracture risk factors and long term medications $(p<0.02)$, increased parity $(p<$ $0.02)$ and increased lactating period $(\mathrm{p}<0.00)$. There is a significant association between the fracture risk factors, Vitamin D Deficiency $(\mathrm{p}<0.07)$, need for arm support $(\mathrm{p}<$ $0.07)$ and lack of exercises $(\mathrm{p}<0.08)$.

Osteoporosis classification based on MFRAT and BMD (Table 3) and significant risk factors (Figure 1). Among the 35 women, 14 women were in the moderatehigh risk category for the occurrence of a fracture or osteoporosis according to the MFRAT. Five women showed early Osteoporotic risk or marked changes on the BMD. The determinants of moderate risk factors are Vitamin D Deficiency, long term medication, need for arm support, lack of exercise, premenopausal, increased lactation and parity (Figure 1).

\section{DISCUSSION}

In this Omani women population, there is a combination of environmental, genetic and lifestyle factors that affect the occurrence of Osteoporosis. Omani women with significantly low BMD results were in the premenopausal age, had longer lactation period and had increased parity. These women also had Vitamin D Deficiency (VDD) and were on long term medications. Pre-menopausal women with low BMD have a significant underlying cause of risk factors $[17,18]$. There is a need for pre-menopausal Osteoporotic risk assessment as one third to one half of women's bone loss can be attributed to menopause, It is important to take early measures to reduce bone loss in early middle age women [19]. The role of Vitamin D in bone health has persistently found to be in the literature $[8,19]$. VDD among women precipitates or exacerbates Osteopenia and Osteoporosis [20-22]. VDD is common in the Middle East, India, China and Japan due to the socio-economic, life-style and environmental conditions [23]. Among these determinants, the significant risk factors among Omani women are non-exposure to sunlight at an early age; complete clothing covering the body (e.g. abhaya, veil, hijab), multiparity, long period of lactation, short birth intervals, sedentary life, poor dietary intake, and lack of exercise. Parity and lactation have detrimenttal effects on bone density of women in developing countries [24-26]. Lactation is associated with loss of maternal calcium [27]. These factors may have subsequent health consequences.

The need for arm support to raise from the chair/bed/ floor, lack of exercise and poor use of dairy products was cited by Omani women who also showed early Osteoporotic changes with BMD testing. There is a relationship between decreased activity levels and bone thinning [28-30]. Low levels of exercise among the perimenopausal Omani women will increase the risk for fracture. Women with a sedentary lifestyle had an increased tendency to sustain a fracture. One the study showed higher percentage of Jewish women with "low or no physical activity like swimming and fitness" at high risk for frac- 
Table 2. Clinical characteristics among Omani women.

\begin{tabular}{|c|c|c|c|c|c|c|}
\hline \multirow{2}{*}{ Clinical Characteristics } & \multirow{2}{*}{ Categories } & \multicolumn{2}{|c|}{ MFRAT $(\mathrm{N}=35)$} & \multicolumn{2}{|c|}{$\operatorname{BMD}(\mathrm{N}=11)$} & \multirow{2}{*}{$\mathrm{p}$} \\
\hline & & $\mathrm{F}$ & $\%$ & $\mathrm{~F}$ & $\%$ & \\
\hline \multirow{2}{*}{ Prior Fragility Fracture or Osteoporosis } & Yes & 3.0 & 8.6 & 3.0 & 27.3 & \multirow{2}{*}{0.32} \\
\hline & No & 32.0 & 91.4 & 8.0 & 72.7 & \\
\hline \multirow{2}{*}{ Vitamin D Deficiency } & Yes & 13.0 & 37.1 & 6.0 & 54.5 & \multirow{2}{*}{$0.07^{* *}$} \\
\hline & No & 22.0 & 62.9 & 5.0 & 45.5 & \\
\hline \multirow{2}{*}{$\begin{array}{c}\text { Systemic Illness (Endocrine, Skeletal, Ovarian, } \\
\text { Reproductive) }\end{array}$} & Yes & 7.0 & 20.0 & 5.0 & 45.5 & \multirow{2}{*}{0.63} \\
\hline & No & 28.0 & 80.0 & 6.0 & 54.5 & \\
\hline \multirow{2}{*}{ Long Term Medications (Estrogen, Vitamin D) } & Yes & 6.0 & 17.1 & 6.0 & 54.5 & \multirow{2}{*}{$0.02^{*}$} \\
\hline & No & 29.0 & 82.9 & 5.0 & 45.5 & \\
\hline \multirow{2}{*}{ Fracture after 40 Years } & Yes & 4.0 & 11.4 & 4.0 & 36.4 & \multirow{2}{*}{0.48} \\
\hline & No & 31.0 & 88.6 & 7.0 & 63.6 & \\
\hline \multirow{2}{*}{ Mother's Fracture after Age 40} & Yes & 8.0 & 22.9 & 7.0 & 63.6 & \multirow{2}{*}{0.22} \\
\hline & No & 27.0 & 77.1 & 4.0 & 36.4 & \\
\hline \multirow{2}{*}{ Family Pathological Fracture } & Yes & 3.0 & 8.6 & 3.0 & 27.3 & \multirow{2}{*}{0.67} \\
\hline & No & 32.0 & 91.4 & 8.0 & 72.7 & \\
\hline \multirow{3}{*}{ Parity/Number of Children } & 0 & 14.0 & 40.0 & 1.0 & 9.1 & \multirow{3}{*}{$0.02^{*}$} \\
\hline & 1 to 3 & 13.0 & 37.1 & 4.0 & 36.4 & \\
\hline & 4 or more & 8.0 & 22.9 & 6.0 & 54.5 & \\
\hline \multirow{2}{*}{ Duration and Frequency of Lactation } & $<1$ year & 19.0 & 54.3 & 5.0 & 45.5 & \multirow{2}{*}{$0.00^{*}$} \\
\hline & $1-2$ years & 16.0 & 45.7 & 6.0 & 54.5 & \\
\hline \multirow{3}{*}{ Menstrual Status } & Premenopausal & 22.0 & 62.9 & 7.0 & 63.6 & \multirow{3}{*}{0.35} \\
\hline & Menopausal & 4.0 & 11.4 & 2.0 & 18.2 & \\
\hline & Menstruation & 9.0 & 25.7 & 2.0 & 18.2 & \\
\hline
\end{tabular}

Significant at ${ }^{*} \mathrm{p}<0.05$ and ${ }^{* *} \mathrm{p}<0.10$. Modified Fracture Risk Assessment Tool (MFRAT), Bone Mineral Densitometry (BMD), F-Frequency.

Table 3. Osteoporosis classification among Omani women.

\begin{tabular}{cllc}
\hline Diagnostic Tool & Osteoporosis Classification & No. & $\%$ \\
\hline & Normal Bone Density: $>-1$ & 6.0 & 54.5 \\
Fracture Risk & Osteopenia: -1 to -2.5 & 3.0 & 27.3 \\
Based on BMD & Osteoporosis: $<-2.5$ & 1.0 & 9.1 \\
$\mathrm{~N}=11$ & Severe Osteoporosis: $<2.5+$ Fragility Fracture & 1.0 & 9.1 \\
& Low Risk: 0 - 9 & 21.0 & 60.0 \\
Fracture Risk Score & Moderate Risk: $10-19$ & 11.0 & 31.4 \\
Based on MFRAT & High Risk: 20 - 34 & 3.0 & 8.6 \\
\hline N $=35$ & De & De & 3.0 \\
\hline
\end{tabular}

*T-score is the measurement of Bone Mineral Densitometry (BMD) by Dual Energy X-Ray Absorptiometry (DEXA) scan (World Health Organization 1994). Modified Fracture Risk Assessment Tool (MFRAT).

ture compared to lower percentage among women in United States [30-32]. The high prevalence of low BMD $(45.5 \%)$ and moderate-high-risk scores $(40 \%)$ on MFRAT show that Omani women are at an increased risk for developing fractures or Osteoporosis.

The authors attributed poor bone health among premenopausal Omani women to factors such as increased parity, duration and frequency of lactation period, Vitamin D Deficiency, on long term medications, need for arm support to rise from chair, and lack of exercises. These factors were found to be important determinants of BMD $(\mathrm{p}<0.05)$. Hence there is a need to develop a cultural specific risk assessment tool to evaluate risk of fracture among this women population for early identifica- 


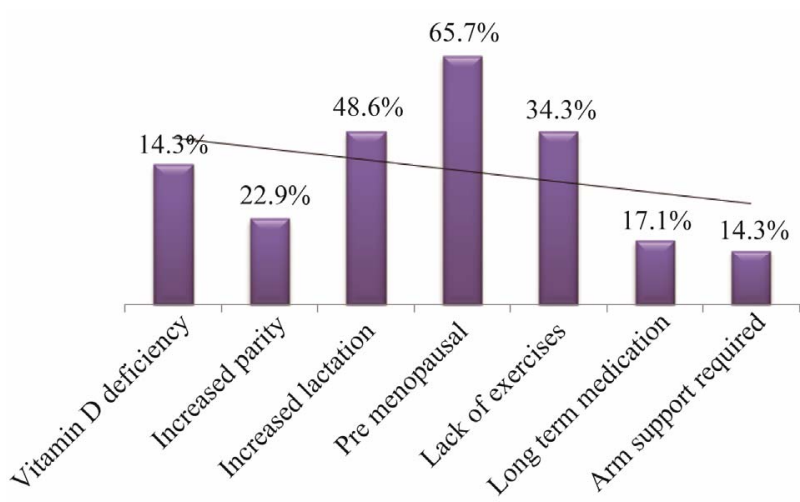

Figure 1. Significant fracture risk factors of Osteoporosis among omani women.

tion, screening and intervention.

\section{CONCLUSIONS}

The increased parity, longer duration and increased frequency of lactation, premenopausal, presence of VDD and low levels of physical activity prevalent among Omani women contributed to early calcium depletion and bone emptying thus leading to low BMD. Nearly $45.5 \%$ of the women had low BMD showing rapid bone mass loss and risk of fracture which highlights the need for further elucidation and research, educational programs for pre-menopausal Omani women. All premenopausal women should have consultation and counseling about lifestyle risk factors, exercise and maintenance of adequate Calcium and Vitamin D intake [20,33]. Early identification of women at risk, early diagnosis and intervention can be directed at preventing the occurrence of the first fragility fracture. A culturally sensitive risk assessment tool is required for early screening, detection and referral, to motivate the local women for periodic risk assessment and engage in health seeking behaviors $[34,35]$. Fracture risk assessment tools should incorporate information about pregnancy and duration of lactation [17].

Virtually all of the risk assessment tools reviewed are not relevant or suitable for Arab women to identify rapid bone loss or low bone mass. Culturally sensitive risk assessment instruments are needed for efficient identification of women most likely to have low BMD. Nurses can further help women by providing education and support to improve the adherence to Osteoporotic medication and lifestyle interventions to reduce fractures and improve quality of life among women. Majority of the Arab women remain undiagnosed and unaware of the importance of early recognition and preventive measures of Osteoporosis. Simple tools are effective in selecting women for BMD measurement and expensive specialized investigations, reducing modifiable risk factors and considering early treatment among high-risk groups [36].
The key for prevention of Osteoporosis lies in creating and using specifically designed tools for early detection and subsequently managing the underlying cause with an individualized approach.

\section{IMPLICATIONS FOR NURSING PRACTICE}

Nurses and nurse educators should have an opportunity to take the lead in promoting bone health through screening and, where appropriate, intervention, referral, and patient education $[31,32]$. Nurses must be sensitized to the need for assessing the risk for fracture or osteoporosis which will help to drastically reduce the care giver burden and ensure cost-effective measure for provision of health care. Primary care prevention is recommended with 5 universal recommendations to promote bone health $[19,32,33]$ for women. For postmenopausal women who are not deemed high risk, the recommendation is reassessment of fracture risk every 5 years $[18$, 34,35]. While concerns about Osteoporosis continue in this region and around the country, the debate about appropriate culturally specific risk assessment screening and management approaches continues. Nurses caring for high risk Omani women should be aware of the prevalence of Osteoporosis and use the culturally specific risk assessment tool and consider BMD testing and early preventive measures. Because the prevalence of Osteoporosis and fragility fracture is high and because diagnostic and therapeutic tools are available, all primary care nurses should take an active role in early identification and screening of Osteoporosis, with the objective of decreasing the disease burden of Osteoporosis and fracture.

\section{AUTHORS' CONTRIBUTIONS}

All authors have participated in the conception and design of the study, and analysis and interpretation of data. MSD, CI and RV drafted the manuscript and provide analysis and interpretation. AA, SB, AT and $\mathrm{HN}$ reviewed the literature and acquired the data using the study protocols. All authors have critically appraised and reviewed the paper for important intellectual content, and final approval of the version to be submitted.

\section{ACKNOWLEDGEMENTS}

We thank the College of Nursing Sultan Qaboos University and the Department of Radiology Sultan Qaboos University Hospital, subject experts who validated the tool and the women participants for their support.

\section{REFERENCES}

[1] WHO (2004) Scientific group on the assessment of 
Osteoporosis at primary health care level. World Health Organization, Geneva.

[2] National Osteoporosis Foundation (2008) Clinician's guide to prevention and treatment of Osteoporosis. National Osteoporosis Foundation, Washington DC.

[3] National Osteoporosis Foundation (1998) Osteoporosis: Review of the evidence for prevention, diagnosis, and treatment and cost effectiveness analysis. Osteoporosis International, 8, S3-6.

[4] Cummings, S.R. and Melton, L.J. (2002) Epidemiology and outcomes of osteoporotic fractures. The Lancet, 359, 1761-1767.

[5] WHO (1994) Assessment of fracture risk and its application to screening for postmenopausal Osteoporosis: Technical report series 843 . WHO, Geneva.

[6] Kanis, J.A. and Glüer, C.C. (2000) An update on the diagnosis and assessment of Osteoporosis with densitometry. International Osteoporosis Foundation. Committee of Scientific Advisors, Osteoporosis International, 11, 192-202. doi:10.1007/s001980050281

[7] Kanis, J.A., Johnell, O., Oden, A., Jönsson, B., De La, C. and Dawson, A. (2000) Risk of hip fracture according to the World Health Organization criteria for osteopenia and osteoporosis. Bone, 27, 585-590.

[8] Collins-Fulea, C., Klima, K. and Wegienka, G.R. (2012) Prevalence of low Vitamin D levels in an urban Midwestern obstetric practice. Journal of Midwifery and Women's Health, 57, 439-444. doi:10.1111/j.1542-2011.2012.00167.x

[9] WHO (1994) Assessment of fracture risk and its application to screening for postmenopausal osteoporosis: Technical report series 843 . WHO, Geneva.

[10] Franklin, D., Shuler, J.M., Conjeski, A. and Rhonda L.H. (2011) Incorporating the WHO FRAX assessment tool into nursing practice. American Journal of Nursing, 111, 59-62. doi:10.1097/01.NAJ.0000403369.05047.31

[11] WHO (2011) Fracture risk assessment tool (FRAX). World Health Organization Collaborating Centre for Metabolic Bone Diseases, Geneva.

[12] Cryer, C. and Patel, S. (2002) Primary care strategy for Osteoporosis and falls and national Osteoporosis society falls, fragility and fractures. NOSF, London.

[13] Black, D.M., Steinbuch, M., Palermo, L., Dargent-Molina, P., Lindsay, R., Hoseyni, M.S. and Johnell, O. (2001) An assessment tool for predicting fracture risk in postmenopausal women. Osteoporosis International, 12, 519-528. doi: $10.1007 / \mathrm{s} 001980170072$

[14] Cadarette, S.M. (2000) Development and validation of the Osteoporosis Risk Assessment Instrument (ORAI) to facilitate selection of women for bone densitometry. Canadian Medical Association Journal, 162, 1289-1294.

[15] Handa, R., Kalla, A.A. and Maalouf, G. (2008) Osteoporosis in developing countries. Best Practice and Research Clinical Rheumatology, 22, 693-708. doi:10.1016/i.berh.2008.04.002

[16] Nelson, H.D., Haney, E.M., Dana, T., Bougatsos, C. and Chou, R. (2010) Screening for Osteoporosis: An update for the US preventive services task force. Annals of Inter- nal Medicine, 153, 99-111.

[17] Ashok, K.B. (2010) Management of Osteoporosis in a premenopausal woman. Best Practice \& Research Clinical Rheumatology, 24, 313-327.

[18] Wu, F., Mason, B., Horne, A., et al. (2002) Fractures between the ages of 20 and 50 years increase women's risk of subsequent fractures. Archives of Internal Medicine, 162, 33-36.

[19] Schoor, N.M.V. and Lips, P. (2011) Worldwide Vitamin D status. Best Practice \& Research Clinical Endocrinology \& Metabolism, 25, 671-680. doi:10.1016/j.beem.2011.06.007

[20] Holick, M.F. (2007) Vitamin D deficiency. The New England Journal of Medicine, 357, 266-281. doi:10.1056/NEJMra070553

[21] International Osteoporosis Foundation and International Society for Clinical Densitometry (2011) Joint task force "ISCD IOF FRAX Initiative". Interpretation and use of FRAX in clinical practice.

[22] International Osteoporosis Foundation (2004) The facts about osteoporosis and its impact. International Osteoporosis Foundation, Nyon.

[23] Lips, P. (2007) Vitamin D status and nutrition in Europe and Asia. The Journal of Steroid Biochemistry and Molecular Biology 103, 620-625. doi:10.1016/j.jsbmb.2006.12.076

[24] Allali, F., Maarouf, H. and Aichaoui, S.E. (2007) Influence of parity on bone mineral density and peripheral fracture risk in moroccan postmenopausal women. $M a-$ turitas, 57, 392-398. doi:10.1016/j.maturitas.2007.04.006

[25] Jang, S.N., Choi, Y.H. and Choi, M.G. (2006) Prevalence and associated of Osteoporosis among postmenopausal women in Chuncheon: Hallym aging study (HAS). Journal of Preventive Medicine and Public Health, 39 389- 396.

[26] Vu, T.T., Nguyen, C.K. and Nguyen, T.L. (2010) Determining the prevalence of Osteoporosis and related factors using quantitative ultrasound in Vietnamese adult women. American Journal of Epidemiology, 161, 824-830.

[27] National Guideline Clearinghouse (NGC) (2011) Guideline synthesis: Screening and risk assessment for Osteoporosis in postmenopausal women. http://www.guideline.gov.

[28] Dornemann, T.M., McMurray, R.G., Renner, J.B. and Anderson. J.J. (1997) Effects of high-intensity resistance exercise on bone mineral density and muscle strength of 40 - 50-year-old women. The Journal of Sports Medicine and Physical Fitness, 37, 246-251.

[29] National Osteoporosis Foundation (NOF) (2002) America's bone health: The state of Osteoporosis and low bone mass in our nation. National Osteoporosis Foundation, Washington DC.

[30] Heinonen, A., Oja, P., Sievanen, H., Pasanen, M. and Vuori, I. (1998) Effect of two training regimens on bone mineral density in healthy perimenopausal women: A randomized controlled trial. Journal of Bone and Mineral Research, 13, 483-490. doi:10.1359/jbmr.1998.13.3.483 
[31] Poole, K. and Compston, J. (2006) Osteoporosis and its management. British Medical Journal, 333, 1251-1256. doi:10.1136/bmj.39050.597350.47

[32] US Preventive Services Task Force (2011) Screening for Osteoporosis: Recommendation statement. American Family Physician, 83, 1197-1200.

[33] Salih, F.M. (2004) Effect of clothing varieties on solar photosynthesis of previtamin D3: An in vitro study. Photodermatol Photoimmunol Photomed, 20, 53-58. doi:10.1111/j.1600-0781.2004.00068.x

[34] American College of Preventive Medicine (2009) Screen- ing for Osteoporosis in the adult US population: ACPM position statement on preventive practice. American Journal of Preventive Medicine, 36, 366-375.

[35] Dawson-Hughes, B., Tosteson, A.N.A. and Melton, I.L, (2008) Implications of absolute fracture risk assessment for Osteoporosis practice guidelines in the USA. Osteoporosis International, 19, 499-458.

[36] Werner, P., Olchovsky, D., Shemi, G. and Vered, I. (2003) Osteoporosis health-related behaviors in secular and orthodox israeli jewish women. Maturitas, 46, 283-294. doi:10.1016/S0378-5122(03)00197-X 